UDC $61 ; 613.2 ; 614 ; 615$

DOI: $10.21668 /$ health.risk/2020.3.17.eng

Research article

\title{
ISOLATION AND CHARACTERIZATION OF STAPHYLOCOCCUS AUREUS FROM TWO LARGE-SCALE FOOD POISONING OUTBREAKS IN VIETNAM
}

\section{Lam Quoc Hung ${ }^{1}$, Huong Minh Nguyen ${ }^{3}$, Ta Thi Yen², Le Vinh Hoa², Tran Hong Ba ${ }^{2}$, Pham Le Quyen ${ }^{2,4}$, Do Thi Thu Huong, Nguyen Thanh Trung ${ }^{2}$, Le Thi Hong Hao ${ }^{2}$}

${ }^{1}$ Vietnam Food Administration, 135 Pho Nui Truc Str., Giang Vo, Ba Dinh, Hanoi, Vietnam

${ }^{2}$ National Institute for food control, NIFC-Vietnam, 65 Pham Than Duat Str., Hanoi, Vietnam

${ }^{3}$ Institute of Biotechnology, Vietnam Academy of Science and Technology, 18 Hoang Quoc Viet Str.,

CauGiay, Hanoi, Vietnam

${ }^{4}$ Quang Binh Center for Disease Control and Prevention, 3150 Rampart Road Str., Fort Collins, USA

${ }^{5}$ National Agro-Forestry Fisheries Quality Assurance Department, 10 Nguyen Kong Hoan Str., Ba Đình, Hanoi, Vietnam

In Vietnam and around the world, Staphylococcus aureus remains a major hazard of food safety and food poisoning. S. aureus is present in many places and easily contaminates food production during processing chains.

In this study, we successfully isolated S. aureus strains from suspected samples of two food borne poisoning outbreaks in Ha Giang and Vinh Phuc in 2017 and 2018, respectively. The collected samples were examined for presence of staphylococcal enterotoxins (SEs) by using $3 M^{T M} T E C R A^{T M}$ Staph Enterotoxin kit, from there all the samples were positive with SEs. Different strains of S. aureus were isolated and then confirmed by MALDI-TOF technique. Those strains then were stored in Brain heart solution with $15 \%$ glycerol until further analysis.

Our results identified three STs, ST96, ST88 (spa type t7558), and ST72 (spa type t3092), were responsible for two outbreaks. Two virulence genes detected from the above strains were sea and sec. Furthermore, these strains are test for antibiotic resistance susceptibility with commonly antibiotics. Penicillin are found to be resisted by all three STs, in particularly, ST96 and ST88 are both resistant to erythromycin while ST72 is resistant to gentamicin.

Taken together, our study highlights the usefulness of molecular characterization to study and monitor bacterial pathogens associated with food poisoning outbreaks in Vietnam.

Key word: antibiotic-resistant, food poisoning, $\beta$-lactamase, ESBL, ampC $\beta$-lactamases, Staphylococcus areus, MLST, Spa genes, staphylococcal toxins.

(C) Lam Quoc Hung, Huong Minh Nguyen, Ta Thi Yen, Le Vinh Hoa, Tran Hong Ba, Pham Le Quyen, Do Thi Thu Huong, Nguyen Thanh Trung, Le Thi Hong Hao, 2020

Lam Quoc Hung - PhD, Head of Department of Food poisoning monitoring (e-mail: lamquochungmoh@gmail.com; tel.: (+849) 133-19-936; ORCID: https://orcid.org/0000-0002-0158-8905).

Huong Minh Nguyen - PhD, Institute of Biotechnology (e-mail: nguyen.huong.m@gmail.com; tel.: (+849) 155-62-485; ORCID: https://orcid.org/0000-0001-5302-2973).

Ta Thi Yen - Msc., Researcher (e-mail: yenta@gmail.com; tel.: (+849) 049-59-050; ORCID: https:// orcid.org/0000-0002-3364-4887).

Le Vinh Hoa - Researcher (e-mail: vinhhoa.1vh@gmail.com; tel.: (+843) 630-59-456; ORCID: https://orcid.org/ 0000-0001-5360-4260).

Tran Hong Ba - Researcher (e-mail: ba.pt070488@gmail.com; tel: (+849) 843-16-925; ORCID: https://orcid.org/ 0000-0002-6393-7197).

Pham Le Quyen - Researcher, Laboratory of Food microbiology (e-mail: seulq311@gmail.com; tel.: (+843) 669-55-241; ORCID: https://orcid.org/0000-0002-9528-5293).

Do Thi Thu Huong - Master of science, Head of Biological Laboratory (e-mail: huongicloud13@gmail.com; tel.: (+849) 120-50-135; ORCID: https://orcid.org/0000-0002-2786-0065).

Nguyen Thanh Trung - Master of science, PhD., Candidate, Head of Laboratory of Food microbiology(e-mail: nguyenthanhtrung83@gmail.com; trungnt@nifc.gov.vn; tel.: (+843) 493-63-269; ORCID: https://orcid.org/0000-0002-8732-9911).

Le Thi Hong Hao - PhD., General director of National Institute for Food Control (e-mail: lethihonghao@yahoo.com; tel.: (+849) 042-48-167; ORCID: https://orcid.org/0000-0003-3570-8570). 
According to the WHO annual report in 2014, there are 40 million food poisoning cases reported worldwide. The Asia-Pacific region reports up to more than $50 \%$ of total cases [1]. After Salmonella and Campylobacter, the two most common bacteria associated with food poisoning, Staphylococcus aureus is also a major foodborne pathogen which is identified in up to 241,000 cases each year globally. Along with that, reports from Europe showed that $5 \%$ of food poisoning outbreaks in the continent were caused by $S$. aureus, which led to an annual rate of infection from 0.6 to $0.7 / 100,000$ people (data from 2010 and 2011) [2, 3]. In Vietnam, the situation has not been under control with a total of 677 outbreaks involving 21,002 patients in the fouryear period from 2011 to 2014 [4]. In the first 4 months of 2016, half of the outbreaks counted in Ho Chi Minh city, the largest city in Vietnam, happened in school canteens, and $50 \%$ of them were caused by S. aureus [5].

Staphylococcus aureus is a Gramnegative bacterium belonging to the Staphylococcus genus, which to date includes more than 30 species. Among those, S. aureus is the most frequently associated with food poisoning and the most common causative of foodborne diseases in human and animal in general $[6,7]$. Approximately, $25-30 \%$ of healthy adults carry $S$. aureus asymptomatically, mostly in the nasopharynx and on the skin. S. aureus normally cannot compete with other type of bacteria naturally exist in food, however, due to their ability to withstand living conditions such as high salt concentration (up to $15 \%$ ) and low humidity, S. aureus can survive on human skin or the surface of clothes and multiple apparatus [8-10]. Therefore, for most cases of staphylococcal food poisoning, the contamination route is through contact with infected food handlers, or infected food preparation surface [11].

S. aureus causes food poisoning by producing staphylococcal enterotoxins, which lead to symptoms such as nausea, abdominal pain, vomiting and diarrhea. Up to now, more than 20 types of staphylococcal enterotoxins (SEs) and SE-related toxins have been described, among these SEA, SEB, and SED are the most prevalent in food poisoning cases [11].

In Vietnam, food is still mostly manually prepared by traditional ways all over local markets, restaurants or school canteens before it reaches consumers, increasing the chance of $S$. aureus transmission during food preparation. It is thus necessary to monitor and characterize $S$. aureus strains involved in outbreaks in the region. Multilocus Sequence Typing (MLST) - a technique utilizes variations in several housekeeping genes to group isolates into common sequence types (STs) - has been successfully handle to quickly and accurately identify and characterize pathogenic bacterial and viral strains worldwide. Besides MLST, variations of the virulent gene spa of $S$. aureus have been used successfully to study the prevalence and diversity of this bacterial species [12]. In this study, we employed both MLST and spa typing, together with enterotoxin and antibiotic susceptibility assays to characterize and elucidate the phylogenetic relationship of $S$. aureus strains involving in two food poisoning outbreaks in Vietnam.

\section{Data and methods.}

Food samples. Food samples were collected after the two food poisoning outbreaks had been reported. The first food poisoning outbreak happened at a wedding reception in 2017, in Vinh Phuc province and caused more than one hundred people to be hospitalized. Food items were collected for further investigation and glutinous rice cake was identified as the suspected causative food. The second outbreak was documented in a school canteen in Ha Giang province. The suspected food was minced pork, which might be the reason for the hospitalization of almost two hundred students. All food samples were collected, kept in ice boxes, and transferred to the National Institute for Food Control for bacterial isolation and characterization.

Detection of SEs in food samples. The presence of five major SEs (SEA to SEE) in food samples was detected using $3 \mathrm{M}^{\mathrm{TM}}$ TECRATM Staph Enterotoxin kit (Novatek, Russia, 16215008) following the manufacturer's instruction [13]. In detail, the amount of $25 \mathrm{~g}$ of 
each food sample was homogenized with Tris buffer, $\mathrm{pH} 8.0$ and the supernatant was collected by centrifugation. All samples were confirmed for the presence of peroxidase before $200 \mu \mathrm{L}$ of sample was mixed with test suspension additive solution (containing $2 \mathrm{~g}$ Tween 20 and $0.001 \mathrm{~g}$ thimerosal in $6.0 \mathrm{~mL} \mathrm{H} 2 \mathrm{O}$ ) and incubated at $35-37{ }^{\circ} \mathrm{C}$ for 2 hours, followed by washing and conjugating with distinctive antibody for each type of SEs. Results were interpreted by measuring absorbance values at $414 \pm 10 \mathrm{~nm}$.

Bacterial isolation. Food samples were homogenized in sterile saline buffer at 1:10 ratio, diluted up to $10^{-4}$ fold and $0.1 \mathrm{~mL}$ of each dilution was plated on Bair Packer (BP) agar (Becton, Dickinson, USA, 276840). Plates were incubated at $37^{\circ} \mathrm{C} \pm 1^{\circ} \mathrm{C}$ in $24-48$ hours and black colonies were chosen for coagulase tests.

The identification of coagulase-positive colonies was, then, performed strain by Vitek®-MS (bioMérieux Clinical Diagnostics, France). Confirmed $S$. aureus isolates were kept at $-80{ }^{\circ} \mathrm{C}$ in Brain heart infusion (BHI, Difco, USA, 1104930500) broth supplemented with $15 \%$ glycerol until further analyses.

Antibiotic susceptibility test. Isolates were recovered on blood agar and one pure colony was transferred to BHI broth. Antibiotic susceptibility tests were performed following the Clinical and Laboratory Standards Institute (CLSI) guideline [14]. Of seven antibiotics tested, susceptibilities to oxacillin (OX;1 $1 \mu \mathrm{g})$, erythromycin $(\mathrm{E} ; 15 \mu \mathrm{g})$, gentamicin $(\mathrm{CN} ; 10$ $\mu \mathrm{g})$, tetracycline (TE; $30 \mu \mathrm{g})$, and penicillin $(\mathrm{P} ; 10 \mu \mathrm{g})$ were determined using disc diffusion assay. Where disc diffusion assay was not applied, resistance to methicillin (MET; $5 \mu \mathrm{g}$ ) and vancomycin (VA; $30 \mu \mathrm{g}$ ) was instead determined by minimum inhibitory concentration (MIC) method. Isolates were classified as sensitive, intermediate or resistant in accordance with CLSI breakpoints for each tested antibiotic. Multidrug resistance (MDR) was defined as non-susceptibility to at least one agent in three or more antimicrobial categories [15].

Genomic DNA extraction. Stored isolates were recovered on blood agar before growing overnight in BHI broth at $37^{\circ} \mathrm{C}$ for DNA extraction. From $3 \mathrm{~mL}$ of overnight $S$. aureus culture, genomic DNA was extracted by using GeneJET Genomic DNA Purification Kit (Thermo Fisher Scientific, USA, K0721) in accordance with the manufacturer's instruction. The quality of extracted DNA was assessed using the Nanodrop 1000 instrument (Thermo Fisher Scientific, USA, I594).

Identification of virulence genes. Five classical SE genes sea, seb, sec, sed and see were identified from genomic DNA of $S$. aureus isolates by PCR using primer sequences reported by Johnson and colleagues [16]. Each $25 \mu \mathrm{L}$ polymerase chain reaction (PCR) contained 12.5 $\mu \mathrm{L} 2 \mathrm{x}$ DreamTaq MasterMix (Thermo Fisher Scientific, USA, K0171), 10 pmol of each primer, $100 \mathrm{ng}$ DNA, and sterile water up to the final volume. Final PCR products were analyzed by agarose electrophoresis to detect the presence or absence of specific amplicons. The presence of classical enterotoxins was confirmed by $3 \mathrm{M}^{\mathrm{TM}} \mathrm{TECRA}^{\mathrm{TM}}$ Staph Enterotoxin kit (Novatek, Russia, 16215008) according to the manufacturer's instruction as described above. The presence of mecA and femA was detected by PCR using the specific primers from previous publications (Table 1 ).

Molecular typing and phylogenetic analyses (MLST). MLST and spa typing were done as previously described in Jolley et al. 2018. In detail, primer sequences and PCR conditions used for amplification of the seven housekeeping genes in the MLST scheme were referred from PubMLST [17]. The polymorphic region of spa gene was amplified using the primer pair spa-1113f (TAA AGA CGA TCC TTC GGT GAG C) and spa-1514r (CAG TAG TGC CGT TTG CTT) [18]. PCR products were purified and sequenced using Sanger method by $1^{\text {st }}$ Base DNA Sequencing Services (Singapore). Sequence type (ST) assignment and clustering were done using PubMLST and eBURST, respectively [1, 19]. Geographical distribution and phylogeography analysis were done using Microreact [20]. Spa types were assigned by the SpaServer website and clustered using Based Upon Repeat Pattern (BURP) [21, 22]. 
Table 1

PCR primers for staphylococcal enterotoxin genes, methicillin-resistance genes, and spa typing

\begin{tabular}{|c|c|c|c|}
\hline Gene & Primer & Primer sequence $\left(5^{\prime}-3^{\prime}\right)$ & References \\
\hline \multirow{2}{*}{ sea } & SEA Fw & GCA GGG AAC AGC TTT AGG C & \multirow{2}{*}{ (Veras, et al., 2008) } \\
\hline & SEA Rv & GTT CTG TAG AAG TAT GAA ACA CG & \\
\hline \multirow{2}{*}{ seb } & SEB FW & GTA TGG TGG TGT AAC TGA GC & \multirow{2}{*}{ (Veras, et al., 2008) } \\
\hline & SEB Rv & CCA AAT AGT GAC GAG TTA GG & \\
\hline \multirow{2}{*}{ sec } & SEC FW & CTT GTA TGT ATG GAG GAA TAA CAA & \multirow{2}{*}{ (Veras, et al., 2008) } \\
\hline & SEC Rv & TGC AGG CAT CAT ATC ATA CCA & \\
\hline \multirow{2}{*}{ sed } & SED Fw & GTG GTG AAA TAG ATA GGA CTG C & \multirow{2}{*}{ (Veras, et al., 2008) } \\
\hline & SED Rv & ATA TGA AGG TGC TCT GTG G & \\
\hline \multirow{2}{*}{ femA } & FemA Fw & AAA GCA CAT AAC AAG CG & \multirow{2}{*}{ (Veras, et al., 2008) } \\
\hline & FemA Rv & GAT AAA GAA ACC AGC AG & \\
\hline \multirow{2}{*}{ mесA } & MecA Fw & TGCTATCCACCCTCAAACAGG & \multirow{2}{*}{ (Yoshida, et al., 2003) } \\
\hline & MecA Rv & AACGTTGTAACCACCCCAAGA & \\
\hline \multirow{2}{*}{ spa } & spa-1113f & TAA AGA CGA TCC TTC GGT GAG C & \multirow{2}{*}{$\begin{array}{c}\text { (Strommenger, et al., } \\
\text { 2006) }\end{array}$} \\
\hline & spa-1514r & CAG TAG TGC CGT TTG CTT & \\
\hline
\end{tabular}

Results and discussion.

Case description and isolate characterization. Two staphylococcal food poisoning outbreaks occurred independently in north Vietnam between 2017 and 2018 (Table 2). The first outbreak happened at a wedding in Vinh Phuc province in 2017, causing 152 guests to be hospitalized. The other outbreak, occurred at a primary school, happened in October 2018. At the second outbreak in $\mathrm{Ha}$ Giang, 279 students were at risk while 170 were hospitalized. Common symptoms in all outbreaks included diarrhea, nausea and vomiting, reported from 2 to 6.5 hours after eating. All patients successfully recovered. Three presumptive $S$. aureus isolates were identified from remaining food samples. Isolates found in samples were kept for further investigation.
Virulence genes and antibiotic resistance pattern of isolates. According to our results, two isolates, designated 388 and 389, were identified from the first outbreak, while, only one isolate, $24 \mathrm{ND}$, was identified in the second outbreak (Table 3). All isolates were coagulase positive. Furthermore, PCR was performed in order to detect the presence of classical SE genes in all isolates. The first outbreak appeared to be caused by two different $S$. aureus strains, one carrying sea toxin genes and femA, and the other having sec and femA. The only $S$. aureus strain identified in the second outbreak also carried femA gene, besides sec. The presence of classical SE toxins in all isolates was confirmed by $3 \mathrm{M}^{\mathrm{TM}} \mathrm{TECRA}^{\mathrm{TM}}$ Staph Enterotoxin kit.

Table 2

Epidemiological data from food poisoning outbreaks

\begin{tabular}{|c|c|c|c|c|c|c|}
\hline Outbreak & $\begin{array}{c}\text { Date } \\
\text { (DD/MM/YY) }\end{array}$ & $\begin{array}{c}\text { No. of patients at } \\
\text { risk / No. of hospi- } \\
\text { talized patients / } \\
\text { No. of deaths }\end{array}$ & $\begin{array}{c}\text { Location / } \\
\text { Site }\end{array}$ & $\begin{array}{c}\text { Incubation } \\
\text { period (hour) }\end{array}$ & $\begin{array}{c}\text { Symptoms } \\
\text { (no. of cases) }\end{array}$ & $\begin{array}{c}\text { Causative } \\
\text { Food }\end{array}$ \\
\hline 1 & $20 / 10 / 17$ & $152 / 109 / 0$ & $\begin{array}{c}\text { Vinh Phuc/ } \\
\text { Wedding/House }\end{array}$ & 5 & N,V,S,D & $\begin{array}{c}\text { Glutinous } \\
\text { rice cake }\end{array}$ \\
\hline 2 & $03 / 10 / 18$ & $279 / 170 / 0$ & $\begin{array}{c}\text { Ha Giang/ } \\
\text { Primary school }\end{array}$ & 2 & N,V,S,D & Minced pork \\
\hline
\end{tabular}

$\mathrm{N}$ o t e : $\mathrm{N}$ - nausea; $\mathrm{V}$ - vomiting; $\mathrm{S}$ - Stomachache; D - diarrhea. 
Table 3

Characterization of isolates from food poisoning outbreaks

\begin{tabular}{|c|c|c|c|c|c|c|c|c|}
\hline \multirow{2}{*}{ Outbreak } & Isolate & $\begin{array}{c}\text { Origin } \\
\text { (No. of } \\
\text { isolates) }\end{array}$ & MLST & $\begin{array}{c}\text { ST's } \\
\text { mapped }^{\mathrm{a}}\end{array}$ & $\begin{array}{c}\text { This } \\
\text { study }\end{array}$ & $\begin{array}{c}\text { Classical } \\
\text { toxins }\end{array}$ & $\begin{array}{c}\text { Virulence } \\
\text { genes }\end{array}$ & $\begin{array}{c}\text { Antibiotic } \\
\text { resistance } \\
\text { phenotypes }\end{array}$ \\
\hline \multirow{2}{*}{1} & 388 & FD & 96 & NA & NA & + & coa, sea, femA & E, P \\
& 389 & FD & 88 & t186 & t7558 & + & coa, sec, femA & E, P \\
\hline 2 & 24 ND & FD & 72 & t126 & t3092 & + & coa, sec, femA & CN, P \\
\hline
\end{tabular}

N o t e : FD - food; E - Erythromycin; P - Penicillin; CN - Gentamicin; ${ }^{\text {a }} \mathrm{ST}(\mathrm{s})$ known associated spa type(s), by Ridom Spa Server [22].

In order to examine the extent of antibiotic resistance of all $S$. aureus isolates, antibiotic susceptibility was tested using disc diffusion method and where required, MIC method was perform as instructed in the Clinical and Laboratory Standards Institute (CLSI) 2018 guideline. The tested antibiotics consisted of those commonly used for treatment of staphylococcal food poisoning (oxacillin, erythromycin, gentamicin, tetracycline, penicillin, and vancomycin) in Vietnam. All isolates were found resistant to at least two antibiotics, one of which was penicillin. Both isolates from the first outbreak were also resistant to erythromycin. 24ND, the isolate from the second outbreak, showed resistance to gentamicin and penicillin.

Molecular typing and phylogenetic analysis. Genotyping was performed on all isolates using MLST and spa typing. MLST profiling revealed there were three sequence types (STs), ST96, ST88, and ST72, among three isolates in this study. ST96 and ST88 were responsible for the first outbreak, and ST72 were responsible for the second one. eBURST analysis showed that none of the detected STs formed clonal complexes with one another or any other known STs, even though all three STs were the central most prevalent ST of their respective group, which were formed by known singlelocus variants in PubMLST database. Based on the group definition of PubMLST, ST72 formed a group with 50 others known STs, ST88 and ST96 respectively formed groups with 48, 66 and 7 other STs. ST72 was the most abundant with 120 isolates recorded in PubMLST, followed by ST88 $(n=108)$ and ST96 $(n=3)$ (Figure 1). An

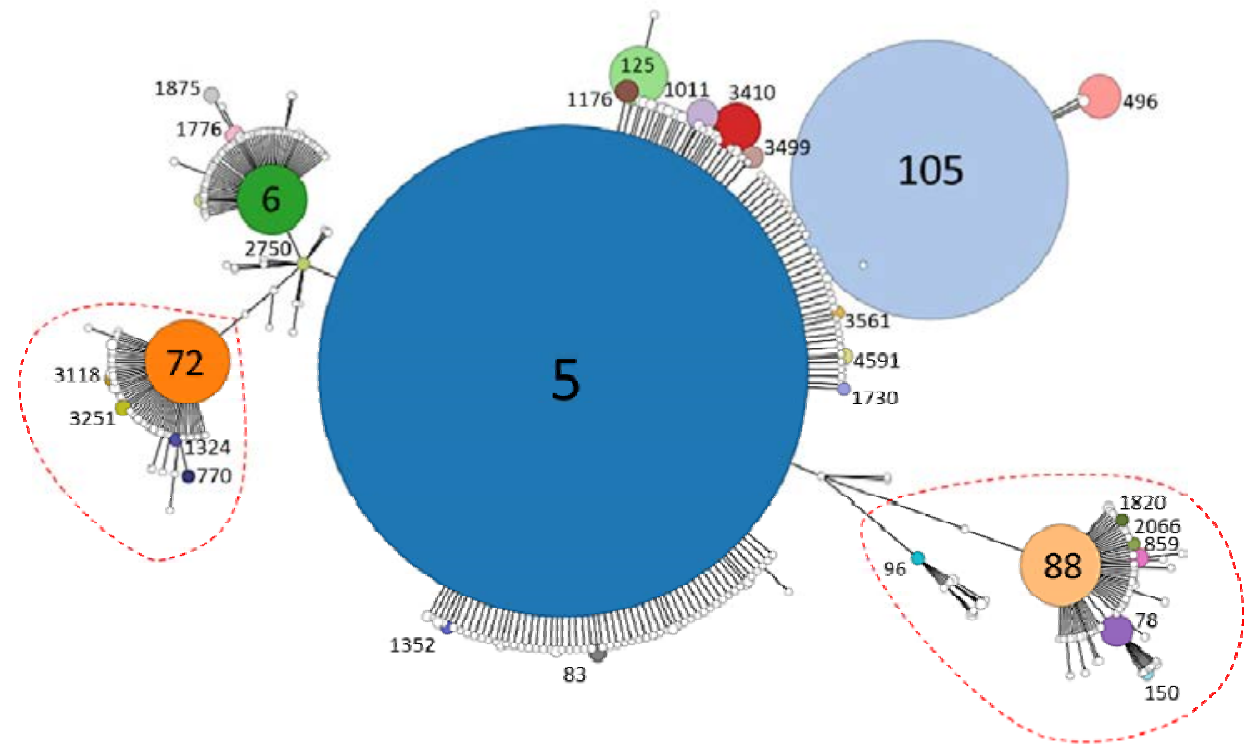

Figure 1. Groups of STs found in this study and their respective single-locus and double-locus variants. STs with more than two known isolates were colored and labeled. Node sizes were numerically correlated with numbers of isolates in each ST. For ST72, ST88 and ST96, all related STs with fewer than two reported isolates were unlisted 

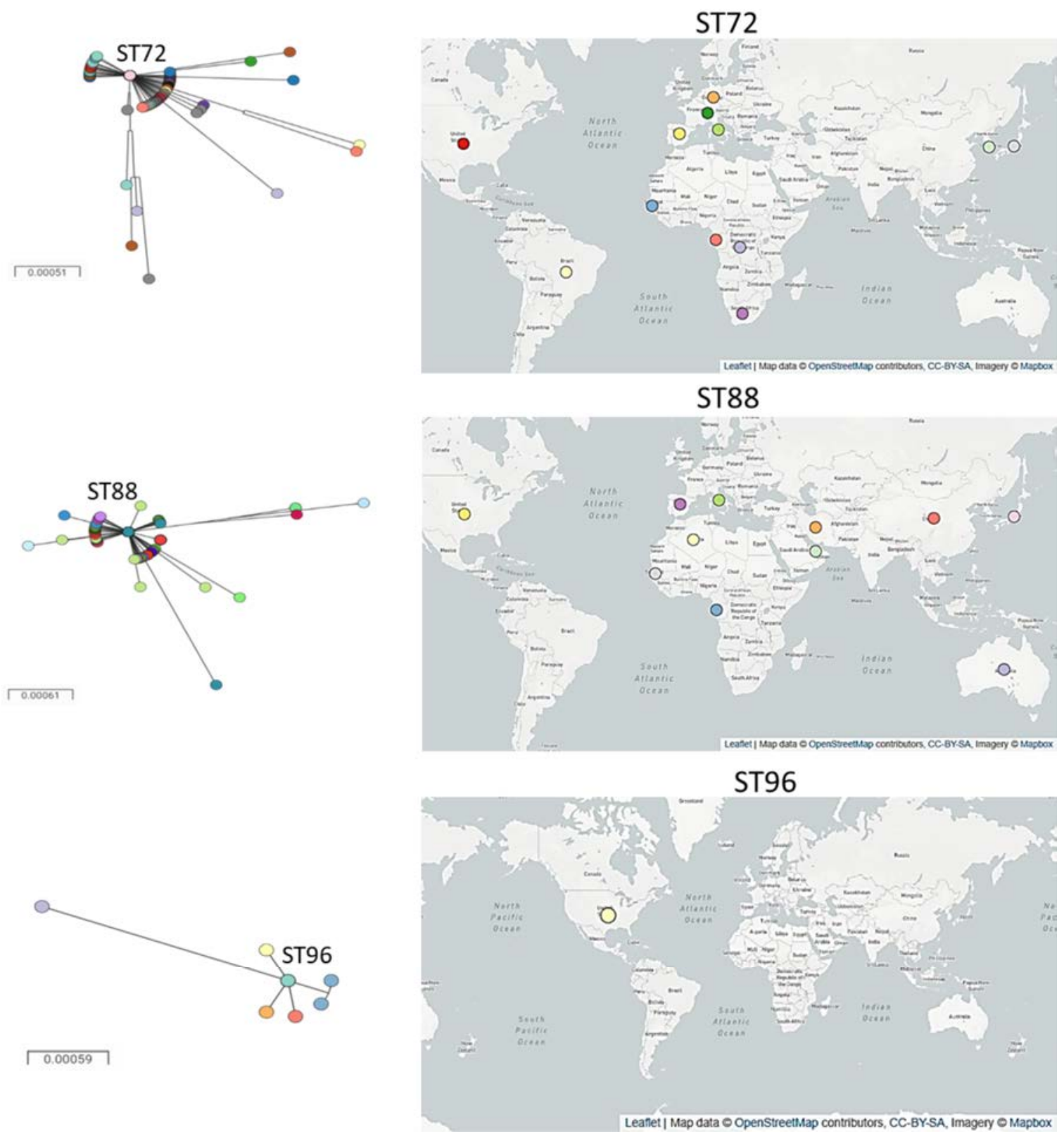

Figure 2. Visualization of phylogeographic trees and geographical distributions of the three STs identified from food poisoning cases in Vietnam between 2017 and 2018: A - phylogeographic trees of each ST showing evolutional relationship and color-labels according to country; B - geographical distribution of the three STs in this study

examination of external nodes, defined as STs sharing at least five identical loci, identified no immediate ancestor of ST72, ST88 and ST96. ST72 has not evolved into any major ST, while ST88 was the ancestor of ST78. ST96 showed branching-out of three STs evolved from it.

Geographical mapping explained the globally distribution of ST88, recorded in all continents. ST72 was found in all continents except for the Oceania. ST96 was the rarest, with only three isolates reported in the USA so far (Figure 2).

In this study, we characterized the causative $S$. aureus strains of two foodborne outbreaks in Vietnam in 2017 and 2018 that led to more 109 and 170 people hospitalized, respectively. Glutinous rice cake and minced pork 
were identified as the causative food, and transmission likely happened during the food preparation process. Using MLST and spa typing methods, three sequence types (STs) involved in two outbreaks were identified, namely ST77, ST88, and ST96. All strains showed resistance to penicillin. In addition, two strains from the outbreak in Vinh Phuc were resistant to erythromycin while the one from the second outbreak in Ha Giang exhibited resistance to gentamicin. Results showed that classical toxins, SEA and SEC, are presented in glutinous rice cake and minced pork. These classic SEs have been recorded as the main toxins causing foodborne outbreaks among more than 20 of SET groups. SEA is predominantly determined around the world in $56.9 \%$ of outbreaks. However, only a small percentage of outbreaks was caused by SEA in conjunction with SEC. In our study, SEA and SEC were identified from the first foodborne outbreak. On the other hand, only SEC was found on minced pork in the second one. This is similar to other reports on staphylococcal food poisoning worldwide [11].

In the United Kingdom, S. aureus led to 359 foodborne outbreaks during the period from 1969 to 1990 . Meat and poultry were the main sources of poisoning [11]. According to European Food Safety Authority report, $S$. aureus caused $5.5 \%$ of outbreaks in the European Union [23].

In this study, we employed both housekeeping genes of MLST scheme and spa vari- ants to analyze strains' phylogenetic relationship. MLST scheme utilized genes encoded for primary metabolism enzymes, while spa is a typical virulence gene, which is normally subjected to higher selection pressure. By combining both schemes, we can accurately estimate strains' evolution. MLST and spa-typing databases are not fully inclusive.

Conclusions. In this study, three STs, including of ST77, ST88, and ST96, were successfully isolated. All isolated strains carry sea gene that produces SEA. According to antibiotic susceptibility testing, all three strains are resistant to penicillin. Moreover, both ST88 and ST96 are resistant to erythromycin, while ST77 is non-susceptible to gentamicin. Geographical mapping data demonstrated that ST96 seems to be an emerging ST which has only been described in outbreaks in the US, whereas the two other STs have been recorded in almost all continents. S. aureus remains a major pathological hazard that rapidly evolves and develops antibiotic resistance, thus continual monitoring of the genetic and antibiotic resistant profiles of circulating $S$. aureus strains in Vietnam is crucial for outbreaks prevention and response.

Acknowledgements. We gratefully thank for being financial sponsor by the Vietnamese Health Ministry.

Funding. This work has been supported by grants from the specific plans for food safety testing.

Conflict of interests. The authors declare there is no any conflict of interests.

\section{References}

1. Kadariya J., Smith T.C., Thapaliya D. Staphylococcus aureus and Staphylococcal Food-Borne Disease: An Ongoing Challenge in Public Health. BioMed Research International, 2014, vol. 214, no. 1, pp. 827965. DOI: 10.1155/2014/82796

2. The European Union Summary Report on Trends and Sources of Zoonoses, Zoonotic Agents and Food-borne Outbreaks in 2010. EFSA Journal, 2012, vol. 10, no. 3, pp. 2597. DOI: 10.2903/j.efsa.2012.2597

3. The European Union Summary Report on Trends and Sources of Zoonoses, Zoonotic Agents and Food-borne Outbreaks in 2011. EFSA Journal, 2013, vol. 11, no. 4, pp. 3129. DOI: 10.2903/j.efsa.2013.3129

4. Joint Annual Health Review 2015. Hanoi, Vietnam Ministry of health, Medical publishing house Publ., 2016, 223 p. 
5. Sub Department of Food Hygiene and Safety of Ho Chi Minh. School food safety assurance report, 2016, $103 \mathrm{p}$.

6. Bhunia A. Foodborne Microbial Pathogens. New York, Springer-Verlag Publ., 2019, 273 p.

7. Microbiology of food and animal feeding stuffs - Horizontal methods for sampling techniques from surfaces using contact plates and swabs. Vietnamese Ministry of Science and Technology, 2009. Available at: https://vanbanphapluat.co/tcvn-8129-2009-vi-sinh-vat-trong-thuc-pham-vathuc-an-chan-nuoi (10.04.2020).

8. Pinchuk I.V., Beswick E.J., Reyes V.E. Staphylococcal Enterotoxins. Toxins, 2010, vol. 2, no. 8 , pp. 2177-2197. DOI: $10.3390 /$ toxins 2082177

9. Bad bug book: handbook of foodborne pathogenic microorganisms and natural toxins. Second Edition. Hanoi, Food and Drug Administration Publ., 2012, 292 p.

10. Chaibenjawong P., Foster S.J. Desiccation tolerance in Staphylococcus aureus. Archives of Microbiology, 2010, vol. 193, no. 2, pp. 125-135. DOI: 10.1007/s00203-010-0653-x

11. Argudín M.Á., Mendoza M.C., Rodicio M.R. Food Poisoning and Staphylococcus aureus Enterotoxins. Toxins, 2010, vol. 2, no. 7, pp. 1751-1773. DOI: 10.3390/toxins2071751

12. Koreen L., Ramaswamy S.V., Graviss E.A., Naidich S., Musser J.M., Kreiswirth B.N. spa Typing Method for Discriminating among Staphylococcus aureus Isolates: Implications for Use of a Single Marker To Detect Genetic Micro- and Macrovariation. Journal of Clinical Microbiology, 2004, vol. 42, no. 2, pp. 792-799. DOI: $10.1128 /$ jcm.42.2.792-799.2004

13. Official Methods of Analysis of AOAC International. 19-th edition. Gaithersburg, AOAC International Publ., 2012, $771 \mathrm{p}$.

14. Performance standards for antimicrobial susceptibility testing. 29-th edition. Maryland, US, Clinical and Laboratory Standards Institute (CLSI) Publ., 2016, 25 p.

15. Magiorakos A., Srinivasan A., Carey R., Carmeli Y., Falagas M., Giske C., Harbarth S., Hindler J. [et al.]. Multidrug-resistant, extensively drug-resistant and pandrug-resistant bacteria: an international expert proposal for interim standard definitions for acquired resistance. Clinical Microbiology and Infection, 2012, vol. 18, no. 3, pp. 268-281. DOI: 10.1111/j.1469-0691.2011.03570.x

16. Johnson W.M., Tyler S.D., Ewan E.P., Ashton F.E., Pollard D.R., Rozee K.R. Detection of genes for enterotoxins, exfoliative toxins, and toxic shock syndrome toxin 1 in Staphylococcus aureus by the polymerase chain reaction. Journal of Clinical Microbiology, 1991, vol. 24, pp. 426-430. DOI: 10.1128/JCM.29.3.426-430.1991

17. Jolley K., Bray J. Maiden M. Open-access bacterial population genomics: BIGSdb software, the PubMLST.org website and their applications. Wellcome Open Research, 2018, vol. 3, pp. 124. DOI: 10.12688/wellcomeopenres.14826.1

18. Strommenger B., Kettlitz C., Weniger T., Harmsen D., Friedrich A.W., Witte W. Assignment of Staphylococcus Isolates to Groups by spa Typing, SmaI Macrorestriction Analysis, and Multilocus Sequence Typing. Journal of Clinical Microbiology, 2006, vol. 44, no. 7, pp. 2533-2540. DOI: $10.1128 / \mathrm{jcm} .00420-06$

19. Feil E.J., Li B.C., Aanensen D.M., Hanage W.P., Spratt B.G. eBURST: Inferring Patterns of Evolutionary Descent among Clusters of Related Bacterial Genotypes from Multilocus Sequence Typing Data. Journal of Bacteriology, 2004, vol. 186, no. 5, pp. 1518-1530. DOI: 10.1128/jb.186.5.1518-1530.2004

20. Argimón S., Abudahab K., Goater R., Fedosejev A., Bhai J., Glasner C., Feil E., Holden M. [et al.]. Microreact: visualizing and sharing data for genomic epidemiology and phylogeography. Microbial Genomics, 2016, vol. 2, no. 11, pp. 1-11. DOI: 10.1099/mgen.0.000093

21. Mellmann A., Weniger T., Berssenbrügge C., Rothgänger J., Sammeth M., Stoye J., Harmsen D. Based Upon Repeat Pattern (BURP): an algorithm to characterize the long-term evolution of Staphylococcus aureus populations based on spa polymorphisms. BMC Microbiology, 2007, vol. 7, article number 98. DOI: 10.1186/1471-2180-7-98

22. Mapping of spa with MLST S. aureus database. Ridom SpaServer, 2020. Available at: http://spa.ridom.de/mlst.shtml (19.03.2020). 
23. The community summary report on trends and sources of zoonoses and zoonotic agents and food-borne outbreaks in the European Union in 2008. EFSA Journal, 2010, vol. 8, no. 1, pp. 1496. DOI: $10.2903 /$ j.efsa.2010.1496

Lam Quoc Hung, Huong Minh Nguyen, Ta Thi Yen, Le Vinh Hoa, Tran Hong Ba, Pham Le Quyen, Do Thi Thu Huong, Nguyen Thanh Trung, Le Thi Hong Hao. Isolation and characterization of staphylococcus aureus from two large-scale food poisoning outbreaks in Vietnam. Health Risk Analysis, 2020, no. 3, pp. 138-146. DOI: 10.21668/health.risk/2020.3.17.eng

Received: 14.04 .2020

Accepted: 17.08 .2020

Published: 30.09.2020 